\title{
Psicologia Comunitária e Política de Assistência Social: Diálogos Sobre Atuações em Comunidades
}

\author{
Community Psychology and Social Assistance Policy: \\ Dialogs on Activities Held in Communities
}

Psicología Comunitaria y Política de Asistencia Social: Diálogos Sobre Actuaciones en Comunidades

Verônica Morais Ximenes, Luana Rêgo Colares de Paula \& João Paulo Pereira Barros

Universidade Federal de Ceará

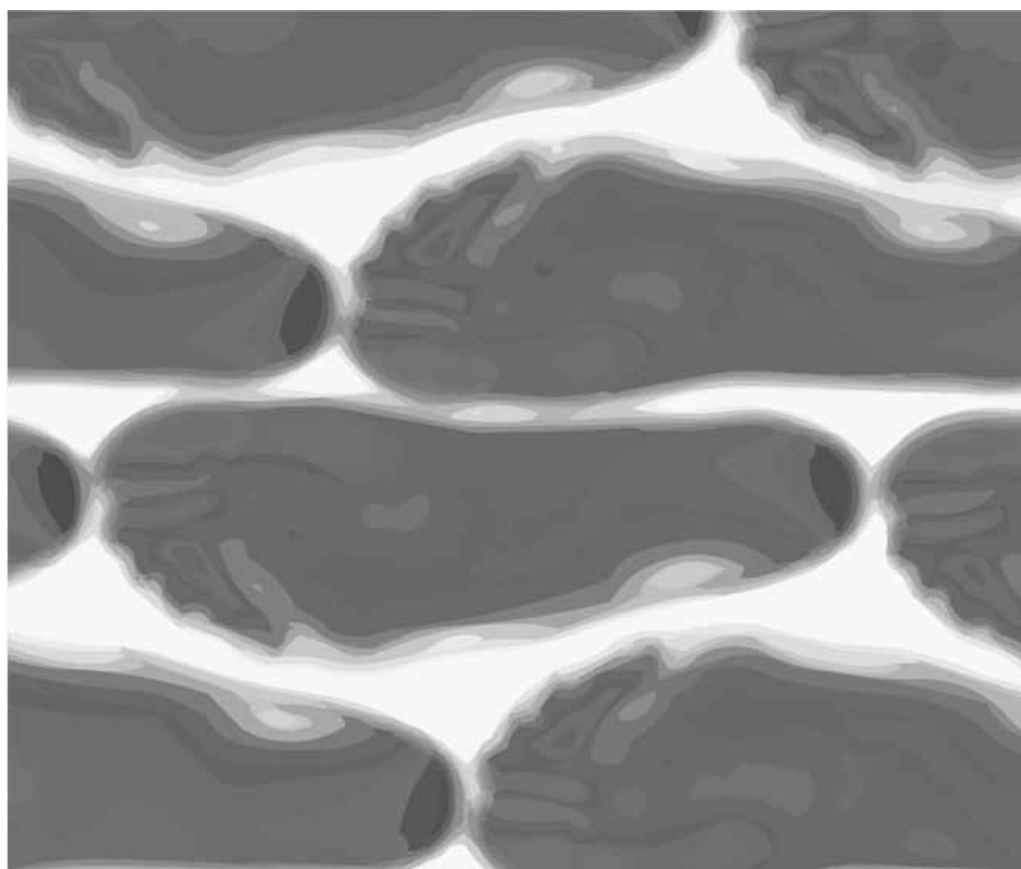


Resumo: Este artigo objetiva traçar diálogos teórico-metodológicos entre a práxis de Psicologia comunitária e a área da assistência social, especificamente em torno da proposta da Proteção Social Básica de fortalecimento da convivência social e comunitária no território onde vivem as famílias assistidas. Assim, são apresentados os contornos da atual política pública de assistência social, situando elementos centrais da Proteção Social Básica. Posteriormente, apontam-se as contribuições da Psicologia comunitária para a leitura e a efetivação de trabalhos coletivos no território de vida das famílias, primando pela problematização de seus processos cotidianos e pela ampliação de vínculos sociais pautados em processos de colaboração. Depreende-se que, para isso, são relevantes os eixos norteadores da práxis de Psicologia comunitária, entre os quais a análise, a vivência e a co-construção de atividades comunitárias, mediante metodologias participativas. Por fim, são ressaltadas também as possíveis limitações contingenciais à aproximação entre a Psicologia comunitária e a Proteção Social Básica.

Palavras-chave: Psicologia comunitária. Política de assistência social. Proteção Social Básica. Atividade comunitária.

\begin{abstract}
This article aims at the outline of theoretical-methodological dialogues between community psychology praxis and the social assistance area, specifically concerning the proposal of Basic Social Protection of strengthening social and community companionship in the assisted families' territory. Therefore, they present the outlines of the social assistance current policies which situate central elements of the Basic Social Protection. The contributions of community psychology are pointed out for reading and for the accomplishment of collective work in the life territory of the families, giving priority to the problematization of their daily processes and to the enlargement of social bonds ruled in collaboration processes. It is understood that, for that objective, there is relevance in the guiding axis of the community psychological praxis, that includes analysis, experience and co-construction of community activities through participative methodologies. Eventually possible contingency restrictions to the approximation between community psychology and the Basic Social Protection are highlighted.
\end{abstract}

Keywords: Community psychology. Social assistance policy. Basic Social Protection. Community activity.

Resumen: Este artículo tiene como objetivo plantear diálogos teórico-metodológicos entre la praxis de Psicología comunitaria y el área de la asistencia social, específicamente en torno de la propuesta de la Protección Social Básica de fortalecimiento de la convivencia social y comunitaria en el territorio donde viven las familias asistidas. Así, son presentados los contornos de la actual política pública de asistencia social, situando elementos centrales de la Protección Social Básica. Posteriormente, se señalan las contribuciones de la Psicología comunitaria para la lectura y a efectuación de trabajos colectivos en el territorio de vida de las familias, primando por la problematización de sus procesos cotidianos y por la ampliación de vínculos sociales pautados en procesos de colaboración. Se aprende que, para eso, son relevantes los ejes orientadores de la praxis de Psicología comunitaria, entre quiénes el análisis, la vivencia y la co-construcción de actividades comunitarias, mediante metodologías participativas. Por fin, son resaltadas también las posibles limitaciones contingenciales a la aproximación entre la Psicología comunitaria y la Protección Social Básica.

Palabras clave: Psicología comunitaria. Política de asistencia social. Protección Social Básica. Actividad comunitaria.

O debate acerca da inserção dos psicólogos em espaços de atuação diferenciados dos tradicionais - entre estes, a clínica psicológica, por exemplo - não é novo. Segundo Yamamoto (2007), tal discussão existe desde a década de 70, em estudos que tanto apresentavam a saturação do mercado no que diz respeito ao modelo do profissional liberal como traziam questionamentos acerca das limitações teórico-metodológicas da Psicologia para a atuação em um contexto de intensas desigualdades sociais, como era o do Brasil e o da América Latina de um modo geral.
Tal debate, que traz como um dos seus pontos nodais a crítica ao elitismo da Psicologia, coincide com o desenvolvimento da Psicologia comunitária no Brasil. Esta se edifica a partir do movimento de uma série de psicólogos que criticavam o viés positivista da Psicologia social até então hegemônica, buscando construir propostas de transformação social (Lane, 2003) a partir de maior aproximação do psicólogo com as dinâmicas do cotidiano da maioria da população.

Paralelamente ao desenvolvimento da Psicologia comunitária, observam-se 
Höfling (2001, p.

31), ao definir

políticas sociais,

explica que

estas "se referem

a ações que

determinam

o padrão de

proteção social

implementado

pelo Estado,

voltadas, em

princípio, para

a redistribuição

dos benefícios

sociais visando à

diminuição das

desigualdades estruturais

produzidas pelo

desenvolvimento socioeconômico". contínuas mudanças nos cenários das políticas públicas brasileiras, e, no bojo dessas novas configurações, um crescimento das possibilidades de atuação do psicólogo no "campo público do bem-estar social" (Yamamoto, 2007). Atualmente, a área da assistência social constitui um dos maiores emblemas desse fato, dadas as suas recentes conformações legais e a conseqüente existência de espaços destinados a psicólogos, por exemplo, nas equipes dos Centros de Referência da Assistência Social (CRAS) unidades públicas estatais responsáveis, desde 2004, pela execução dos programas, projetos e serviços da Proteção Social Básica (PSB).

Em meio à muldimensionalidade de questões que envolvem a Proteção Social Básica e também a pluralidade da Psicologia, este artigo objetiva traçar diálogos teóricometodológicos entre a práxis de Psicologia comunitária e a proposta de Proteção Social Básica relativa ao desenvolvimento de vínculos sociais no território onde vivem as famílias assistidas.

De antemão, importa registrar que, como são entendidos nessa perspectiva, percursos dialógicos não são lineares e necessariamente harmônicos, senão que admitem que uma heterogeneidade de partícipes ora convirja, ora divirja, oscilando entre momentos de maior e de menor conflitualidade na tentativa de fazer com que construções coletivas se estabeleçam. Por isso, os diálogos aqui esboçados serão compostos de pontos a partir dos quais a Psicologia comunitária e a Proteção Social Básica se aproximam e de apontamentos sobre as possíveis limitações dessa aproximação. Para tanto, tem-se uma apresentação dos contornos da assistência social, detendo-se nas propostas concernentes à Proteção Social Básica. Em seguida, apontam-se as possibilidades de contribuições da Psicologia comunitária para a leitura e a efetivação de propostas de desenvolvimento de trabalhos grupais que primem pelo "fortalecimento da convivência familiar e comunitária" (Brasil, 2005a, p. 33). Por fim, são explicitados os possíveis pontos de tensão que se interpõem entre a Psicologia comunitária e a Proteção Social Básica em relação à atuação em comunidades.

\section{Políticas (públicas) sociais e política de assistência social: breve histórico}

As políticas sociais têm suas origens relacionadas ao desenvolvimento das primeiras revoluções industriais, no século XIX, quando o Estado se organiza para responder às demandas sociais produzidas pelo sistema capitalista. Höfling (2001, p. 31), ao definir políticas sociais, explica que estas "se referem a ações que determinam o padrão de proteção social implementado pelo Estado, voltadas, em princípio, para a redistribuição dos benefícios sociais visando à diminuição das desigualdades estruturais produzidas pelo desenvolvimento socioeconômico".

A autora diferencia políticas públicas de políticas sociais, ao enfatizar que aquelas correspondem às ações que devem ser implementadas e mantidas pelo Estado, a partir de um processo que envolve a participação de outras esferas e atores sociais, não podendo, portanto, ser restringidas a políticas estatais. Cumpre mencionar que o desenvolvimento de tais políticas, com vistas à promoção de cidadania, acena para uma rede complexa de ações que envolvem contradições e a coexistência de interesses conflitantes, ganhando nuances diferenciadas de acordo com o contexto socioeconômico e político de cada momento histórico.

No final dos anos 70 e durante os anos 80, o contexto brasileiro caracterizava-se pelo progressivo desgaste do período ditatorial e pelo surgimento de diferentes movimentos sociais que lutavam pelo estabelecimento 
de valores e práticas democráticas. Segundo Costilla (2006, pp. 25-26), nessa época, “a expectativa da sociedade civil de ganhos econômicos e sociais se mostra com clareza na demanda popular majoritária de inclusão de direitos sociais, culturais e políticas públicas". Em meio a essa conjuntura, havia uma crescente discussão em torno das ações assistenciais, até então marcadas por práticas assistencialistas e filantrópicas.

Assim, através da participação de vários atores e movimentos sociais, tem início um processo de discussão e de proposição de uma lei que regulamentasse a assistência a pessoas que viviam em situação de "vulnerabilidade social". Em 1988, tem-se a promulgação da vigente Constituição Federal, e, com ela, a afirmação da assistência social como direito do cidadão e dever do Estado, compondo o tripé da seguridade social, ao lado da saúde e da previdência social. Apesar desse avanço, entretanto, a consolidação da assistência social como política pública não se constituiu inteiramente em uma realidade, visto que, após a promulgação da Constituição de 1988, não houve a concretização de muitos de seus preceitos. Com efeito, esse é um desafio que permanece na atualidade, considerando as fortes marcas clientelistas e assistencialistas que caracterizam a história das práticas assistenciais no Brasil. Sobre essa questão, Behring e Boschetti (2008, pp. 161-162) argumentam:

A assistência social é a política que mais vem sofrendo para se materializar como política pública e para superar algumas características históricas como: morosidade na sua regulamentação como direito...; redução e residualidade na abrangência, visto que os serviços e programas atingem entre $15 \%$ e $25 \%$ da população que deveria ter acesso aos direitos; manutenção e mesmo reforço do caráter filantrópico, com forte presença de entidades privadas na condução de diversos serviços..., e permanência de apelos e ações clientelistas.
Com relação à morosidade na regulamentação, somente em 1993 foi sancionada a Lei Orgânica da Assistência Social (LOAS), ou seja, após cinco anos de vigência da Constituição. Contudo, a inovação conceitual que marcou esse novo aparato normativo não fez com que a assistência social, por vezes, deixasse de se afiliar, nos meandros cotidianos, ao assistencialismo e às modalidades emergenciais de atendimento à população. Por certo, a década de 1990 contribuiu bastante para reforçar o caráter assistencialista tradicionalmente conferido à política em foco. Segundo Behring e Boschetti (2008), nesse período, houve um crescimento do chamado Terceiro Setor, através de parcerias com Organizações Não-governamentais (ONGs) e instituições filantrópicas que passaram a executar políticas desse cunho, em detrimento da intervenção e da responsabilização do Estado. Nas palavras das autoras:

\begin{abstract}
A essa nova arquitetura institucional na área social - sempre ignorando o conceito constitucional de seguridade - se combinou o serviço voluntário, que desprofissionalizava a intervenção nessas áreas, remetendo-as ao mundo da solidariedade, da realização do bem comum pelos indivíduos através de um trabalho voluntário não-remunerado. (Behring \& Boschetti, 2008, p. 154)
\end{abstract}

Percebe-se, assim, que a década de 90 se notabilizou pela ratificação da característica filantrópica das práticas assistenciais brasileiras, nas quais múltiplos agentes se revezam na sua feitura, ao passo que o Estado se exime do seu encargo como principal agente da proteção social do País. Trata-se, pois, de um processo de inversão do pilar de sustentação da seguridade social, mediante a transposição, para a sociedade, da função de provedor, configurando um aspecto central de diferenciação entre o processo de regulação social dos países que integram o denominado Primeiro Mundo - onde se estabeleceu o chamado "Estado Providência" - e os demais países capitalistas periféricos - nos quais se desenvolveu a denominada "Sociedade 
Providência". Dessa forma, a organização que resulta da solidariedade da sociedade civil constitui-se "na protagonista principal na atenção aos despossuídos e destituídos" (Sposati, Falcão, \& Fleury, 1989, p. 3).

Portanto, aliada aos efeitos da então conjuntura político-econômica, é plausível apontar que a co-existência tensional entre perspectivas democráticas assentadas na afirmação dos direitos sociais e uma tradicional cultura política clientelista e patrimonialista limitou maiores reformulações nos sistemas e nas práticas de proteção social. Assim, nas últimas décadas do século $\mathrm{XX}$, o direito à seguridade social garantido constitucionalmente não se efetivou por completo, principalmente no que concerne à assistência social.

Somente em 2004, após as deliberações da IV Conferência da Assistência Social - ocorrida em dezembro de 2003 - consolidouse um processo que visou a efetivar a política de assistência social tal como prevista na Constituição de 1988. Tal processo, encabeçado pelo Ministério do Desenvolvimento Social e Combate à Fome (MDS), através da Secretaria Nacional de Assistência Social (SNAS) e do Conselho Nacional da Assistência Social (CNAS), envolveu a participação de vários segmentos e atores sociais nos "diversos encontros, seminários, reuniões, oficinas e palestras" (Brasil, 2005a, p. 11).

Vale salientar também que esse processo se deu - e continua se dando - em um contexto de vigência de uma gestão que se desenvolve em meio a uma contraditoriedade, na medida em que, ao mesmo tempo em que realiza concessões à ideologia neoliberal, encarrega o Estado de implementar e de desenvolver políticas públicas de proteção social:

...É preciso considerar que a análise dessa "viragem à esquerda" só ganha sentido dentro do contexto contraditório da América
Latina nos últimos 25/30anos, gestado na confluência da democratização e dos processos de ajuste à nova ordem do capital. É o cenário de contradições sociopolíticas entre a ampliação do Estado Democrático, com a instituição de uma 'cultura de direitos' e as restrições do Estado Ajustador, submetido à lógica do mercado, secundarizando o social e atualizando a "cultura da carência." (Carvalho, 2006, p. 143)

É, pois, nesse contexto que surge a atual Política Nacional de Assistência Social (PNAS/2004) e, em seguida, o Sistema Único da Assistência Social (SUAS, 2005), conferindo um esforço em tornar viáveis e efetivas as ações dessa política (Brasil, 2005a, 2005b).

A PNAS/2004 organiza as ações da assistência social em dois níveis de proteção: Proteção Social Básica (PSB) e Proteção Social Especial (PSE). A primeira caracteriza-se pelo atendimento a pessoas e grupos que estejam "em situação de vulnerabilidade social e destina-se ao desenvolvimento de ações que visam ao fortalecimento de vínculos sociais e ao desenvolvimento de potencialidades". Já a segunda é responsável pelo atendimento a pessoas que estão "em situação de risco pessoal e social, por ocorrência de abandono, maus-tratos físicos e, ou, psíquicos, abuso sexual, uso de substâncias psicoativas, cumprimento de medidas socioeducativas, situação de rua, situação de trabalho infantil, entre outras" (Brasil, 2005a, p. 37).

Os programas, projetos e serviços da Proteção Social Básica devem ser desenvolvidos, sobretudo, nos Centros de Referência da Assistência Social (CRAS), cuja equipe mínima sugerida pelo Guia de Orientação Técnica SUAS (Brasil, 2005b) compõe-se, basicamente, de psicólogos e assistentes sociais, além de apoios administrativos. Apesar de tal guia sugerir diretrizes metodológicas para o trabalho nos CRAS, não há uma orientação específica para cada categoria profissional. 
Diante de tal panorama, torna-se importante a reflexão em torno dos recursos teóricos e metodológicos que ambos os profissionais e, nos propósitos deste artigo, que o psicólogo - podem lançar mão para a realização das ações propostas e, em conseqüência, para o alcance dos objetivos da PSB. Para tal, serão tecidas adiante articulações entre as questões-chave que balizam a Proteção Social Básica e alguns pontos conceituais e operativos que configuram a práxis de Psicologia comunitária.

\section{Proteção social básica e Psicologia comunitária: diálogos possíveis}

Sobre esse tópico, faz-se necessário, primeiramente, ressaltar que o desenvolvimento de ações no tecido comunitário é uma premissa claramente evidenciada na atual política de assistência social, isso porque nesta se afirma que a "proteção social exige a capacidade de maior aproximação possível do cotidiano da vida das pessoas, pois é nele que riscos, vulnerabilidades se constituem" (Brasil, 2005a, p. 15).

Complementarmente a essa busca de atuar "com famílias e indivíduos em seu contexto comunitário" (Brasil, 2005a, p. 35), a proposta da PNAS põe em relevo a necessidade de que a perspectiva sob tal dinâmica territorial esteja “...pautada na dimensão ética de incluir os 'invisíveis', os transformados em casos individuais, enquanto de fato são parte de uma situação social coletiva" (Brasil, 2005a, p. 15).

O transcorrer de ações pautadas nesse território suscita a seguinte argüição ao fazer psicológico: nessas condições, que possibilidades são geradas à práxis do psicólogo em se tratando de seu delineamento e de sua direção?

Para iniciar movimentos dentro desse campo de problematização, é oportuno lançar luzes sobre a perspectiva psicológica aqui adotada. Segundo Góis (1994, p. 43), a Psicologia comunitária é
uma área da Psicologia social que estuda a atividade do psiquismo decorrente do modo de vida do lugar/comunidade.... Visa ao desenvolvimento da consciência dos moradores como sujeitos históricos e comunitários, através de um esforço interdisciplinar que perpassa a organização e o desenvolvimento dos grupos e da comunidade.

Como salienta Quintal de Freitas (1998, p. 1), "a visão de homem e a de mundo, assumidas e vividas pelos profissionais, é que se constitui em aspecto crucial na criação ou determinação das possibilidades sobre o como estudar, pesquisar e/ou intervir". A partir da Psicologia comunitária, a compreensão das recorrências e singularidades dos mais variados arranjos microssociais traz à tona o pressuposto ontológico de que o ser humano não somente reage às injunções sociais mas também se constitui em um ator social que participa da criação da vida cotidiana (Montero, 2004).

Com efeito, a investigação-ação do psicólogo volta-se para os processos interacionais que perfazem os modos de vida comunitários, tendo em vista o seu caráter mediador na construção de saberes, práticas e atores sociais. Tais processos, dessa perspectiva, estão interligados complexamente entre si e em intensas, contínuas, mutantes e mutáveis conexões com outros contextos socioculturais.

O deslocamento do psicólogo dos espaços tradicionais para as vicissitudes existentes em espaços de convivência comunitária não se justifica, então, pela extensão do serviço psicológico, nos seus moldes tradicionais, a parcelas socioeconomicamente desfavorecidas da população; explica-se, sim, pela premissa segundo a qual as comunidades possuem uma gama de redes interativas que 
perpassam - junto com outros vetores - a complexa construção de pessoas e grupos que ali vivem, podendo, assim, servir de base para que a práxis psicológica se constitua de modo diametralmente oposto a vieses psicologizantes.

Diante desses esboços conceituais, entendese que a presença do psicólogo nas ações de Proteção Social Básica pode contribuir para ampliar as possibilidades destas, na medida em que permite "uma compreensão mais subjetiva da realidade local, isto é, ver que as localidades são realidades profundamente humanas e simbólicas, sendo por isso um erro pensá-las somente em termos sociológicos e econômicos" (Góis, 2005, p. 73).

Sob esse prisma, de acordo com Sawaia (2004), no terreno polissêmico das discussões em torno da pobreza, dos direitos sociais e da cidadania, há que também se pôr em destaque as singularidades e as referências espaço-temporais das pessoas que vivenciam as expressões multiformes da desigualdade social. Decorre daí, à luz da Psicologia, a atenção para a apropriação/construção de significados, para a produção de sentidos (Zanella, Da Ros, Reis, \& França, 2004), bem como para a emergência da afetividade e do sofrimento ético-político como importantes categorias analíticas na compreensão da dialética exclusão-inclusão social que, ao mesmo tempo, reverbera, singulariza-se e se constitui nas dinâmicas das comunidades.

Dando continuidade aos diálogos possíveis, interessa, ademais, observar que se almeja, nas ações de PSB, enfocar "o desenvolvimento de potencialidades e aquisições e o fortalecimento de vínculos familiares e comunitários" (Brasil, 2005a, p. 33). Concernente a isso, torna-se importante pontuar que o desenvolvimento de ações no espaço comunitário não necessariamente indica ampliação de vínculos sociais, tampouco lineamentos transformadores daquela dinâmica intesubjetiva, mesmo porque tais ações podem se afiliar a diferentes matizes conceituais e políticos.

Nesse sentido, Ximenes, Nepomuceno e Moreira (2007, p. 25), inspiradas por Góis (1994), apresentam três possibilidades de atuação, a saber, assistencialista, tecnicista e comunitário-libertadora. Na primeira, a relação entre o agente externo - nesse caso, o psicólogo - e a comunidade é "paternalista, distanciada e não favorece o processo de análise e reflexão". Tal prática se limita à satisfação de necessidades imediatas e favorece a dependência e a submissão da comunidade. Na atuação tecnicista, há uma relação hierárquica entre o saber do profissional e os erigidos localmente, o que torna a despotencializar práxis emancipatórias.

Finalmente, o tipo de atuação comunitáriolibertador baseia-se na construção compartilhada de conhecimentos de maneira dialógica e colaborativa, na qual se destaca a problematização de saberes e de relações de poder alinhavados e, por vezes, naturalizados no cotidiano. Nessa perspectiva,

...a produção de problemas - antes que sua solução - assume importância crucial, na medida em que as problematizações postas diante de acontecimentos já naturalizados produzem deslocamentos por vezes desconcertantes, que abrem possibilidades de sentido, ações e modos de vida antes impensáveis. (Diehl, Maraschin, \& Tittoni, 2004, p. 410)

Dados os aportes da Psicologia comunitária, a atuação comunitário-libertadora, mais do que as duas primeiras, pode dar corpo ao intento de ampliar vínculos familiares e comunitários sob o prisma da cidadania e da atualização da potência de ação dos atores sociais (Sawaia, 2004), isso porque, nesse tipo, uma heterogeneidade de atores sociais - institucionais ou não - que compõem a dinâmica comunitária é considerada coconstrutora das ações que são desenvolvidas 
No que diz

respeito às diretrizes

metodológicas das ações de Proteção Social Básica, seus profissionais são orientados a

"construir, em conjunto com as famílias, planos de ação que concretizam projetos de vida, a partir de necessidades sociais existentes e expectativas e desejos para o futuro..." (Brasil, 2005b, p. 17). pelo psicólogo e pela equipe multiprofissional com a qual este venha a trabalhar. Dessa forma, tais atores participam ativamente do seu planejamento, da sua execução, da sua avaliação e do seu aprimoramento. Nesse processo, aliás, há que se considerar a possibilidade de que visões distintas estejam presentes - não só quando consideradas as diferenças entre "agentes externos" e "agentes internos" mas também quando se considera a própria diversidade de "agentes internos" que compõe aquele contexto.

No que diz respeito às diretrizes metodológicas das ações de Proteção Social Básica, seus profissionais são orientados a "construir, em conjunto com as famílias, planos de ação que concretizam projetos de vida, a partir de necessidades sociais existentes e expectativas e desejos para o futuro..." (Brasil, 2005b, p. 17). Isso implica a necessidade de "articular o conhecimento da realidade das famílias com o planejamento do trabalho" (Brasil, 2005b, p. 16).

No âmbito da Psicologia comunitária, a análise, a vivência e a co-construção de atividades comunitárias, mediante um método dialógico-vivencial (Góis, 2005), podem figurar como elementos relevantes em função de, pelo menos, dois aspectos: primeiramente, porque podem subsidiar a efetivação das próprias diretrizes então apresentadas; em segundo lugar, porque ampliam o campo de inteligibilidade relativo à atuação do psicólogo nas ações eminentemente grupais da Proteção Social Básica.

O método dialógico-vivencial envolve uma dimensão reflexiva, em que há uma constante problematização das dinâmicas comunitárias - realizada, diga-se de passagem, em interação com os seus moradores - e uma constante abertura do psicólogo à trama relacional que ali se estabelece, a fim de se deixar afetar por suas intensidades. A opção por essa via de atuação alude, portanto, a um contato constante do profissional com os cotidianos que compõem os espaços microssociais em questão, de modo a compreender suas idiossincrasias socioculturais, suas interfaces com outros contextos e os arranjos subjetivos engendrados nessa interface.

Diante disso, a atividade comunitária, conceito sistematizado por Góis (1994, 2005) a partir da teoria da atividade (Leontiev, 1978), assume lugar de destaque na práxis de Psicologia e é considerada referência para esse debate, por propiciar o desenvolvimento dos seus participantes e a potencialização da relação destes com o lugar onde vivem. Tal como conceitua Góis (2005, p. 89), a atividade comunitária realiza-se "por meio da cooperação e do diálogo em uma comunidade, sendo orientada por ela mesma e pelo significado (sentido coletivo) e sentido (significado pessoal) que a própria atividade e a vida comunitária têm para os moradores da comunidade".

O conceito em questão refere-se a espaços de trabalho conjunto em que, a partir de situações-limite identificadas, os agentes de uma comunidade realizam ações em rede cujo objetivo é a melhoria da qualidade de vida coletiva, considerando a pertinência da diversidade nesse processo e o caráter não necessariamente harmonioso nesse curso. Segundo Góis (2005), atividades dessa natureza envolvem processos interacionais mediados que se pautam na transformação do contexto onde se verificam. Podem ser exemplos disso: a ampliação de espaços públicos existentes no território através da organização de momentos de socialização entre os moradores, a elaboração de um projeto de desenvolvimento comunitário, a formação de grupos, a constituição de redes de apoio entre os moradores e a realização de trocas de experiências cujo "tema gerador" provenha da tessitura cotidiana. 
A importância de conhecer as atividades comunitárias já desenvolvidas no contexto onde se realiza a práxis do psicólogo se justifica porque

....analisando e vivenciando a atividade, chegaremos a conhecer não só o processo social e econômico de um lugar como também (e para o psicólogo é o principal) o que pensam os moradores, o que sentem e o que fazem no dia a dia em relação a si mesmos e aos outros. (Góis, 2005, p. 90)

A partir desse prisma e levando em consideração a importância dessas atividades, o psicólogo pode tanto contribuir para o fortalecimento das iniciativas já existentes na comunidade quanto fomentar a criação de novas atividades comunitárias. Essa perspectiva vai ao encontro da orientação metodológica apontada no Guia de Orientação Técnica do SUAS, que sugere que as equipes do CRAS devem conhecer "a situação de organização e mobilização comunitária no território, detectando seus potenciais individuais e coletivos" (Brasil, 2005b, p. 17).

A fim de fomentar atividades comunitárias e articulá-las com os intuitos da Proteção Social Básica, especialmente com a identificação e o desenvolvimento de potencialidades pautadas na constituição de vínculos sociais, a práxis psicológica apresentada pode se orientar pelos seguintes eixos: familiarização com o contexto comunitário, identificação conjunta de necessidades e potencialidades, elaboração de perspectivas de ação e trabalho coletivo pautado na avaliação processual e na sustentabilidade das ações (Montero, 2006). Para tanto, utiliza aportes participativos, como a observação-participante (Góis, 1994; Montero, 2006), a pesquisa-participante e a ação-participante (Góis, 1994), bem como o acompanhamento de grupos comunitários (Góis, 1994; Montero, 2006). Esse aporte metodológico da Psicologia comunitária pode contribuir com a pretensão do CRAS de "realizar trabalhos com grupos de famílias ou seus representantes, fortalecendo a socialização e a definição de projetos coletivos" (Brasil, 2005b, p. 18).

Assim, no desenvolvimento das ações da Proteção Social Básica, o profissional de Psicologia pode utilizar algumas estratégias a fim de conhecer a vida e a dinâmica das famílias e do seu contexto e de estabelecer vínculos imprescindíveis com estes. Cotidianamente, tais estratégias envolvem, por exemplo, a realização de entrevistas individuais e/ou coletivas (Montero, 2006), visitas domiciliares (Barros, 2007), participação em atividades da comunidade, registros de acontecimentos e/ou episódios significativos em diários de campo (Freitas, 1998; Montero, 2006), conhecimento sobre a história do lugar através de conversas informais com moradores, de contatos com lideranças formais e informais e do levantamento de documentos e de outras produções locais (Góis, 1994, 2005) e acompanhamento de grupos (Lane, 2003; Montero, 2004, 2006), entre outras.

Consideradas essas possibilidades aproximativas entre a práxis da Psicologia comunitária e a proposta da Proteção Social Básica, cumpre assinalar também alguns pontos de tensionamentos que podem configurar o diálogo entre ambas. Eis o intuito da próxima seção, que, em vez de se ater a aportes previstos na política de assistência social, destacará elementos que, contingencialmente, atravessam as práticas cotidianas de proteção social básica.

\section{Pontos de tensão nos diálogos entre Psicologia comunitária e Proteção Social Básica}

As considerações sobre possíveis pontos de tensão entre a Psicologia comunitária e a Proteção Social Básica não podem prescindir de reflexões em torno das limitações de 
ambas as práticas - da Psicologia e da política pública - e de sua relação.

No que concerne à política de assistência social, considera-se fundamental a noção de que esta corresponde a "apenas" um vetor da proteção social brasileira, o que significa que não compete somente a ela a responsabilidade pelo atendimento às demandas sociais; portanto, sua prática deve se desenvolver necessariamente em interação com as demais políticas públicas e sociais. É o que sublinham os Conselhos Federais de Psicologia e Serviço Social ao apontarem parâmetros para a atuação de assistentes sociais e psicólogos na política de assistência social:

...é fundamental que os(as) trabalhadores(as) envolvidos na implementação do SUAS tenham clareza das funções e possibilidades das políticas sociais que integram a seguridade social, de modo a não atribuir à assistência social a intenção e o objetivo hercúleo e inatingível de responder a todas as situações de exclusão, vulnerabilidade, desigualdade social. Essas são situações que devem ser enfrentadas pelo conjunto das políticas públicas, a começar pela política econômica, que deve se comprometer com a geração de emprego e renda e distribuição da riqueza. (Conselho Federal de Serviço Social [CFESS] \& Conselho Federal de Psicologia [CFP], 2007, p. 12)

Além disso, uma vez que toda prática social está inserida em uma complexa tessitura histórico-política, o desenvolvimento cotidiano dos programas, projetos e serviços de Proteção Social Básica assume caráter relativo, mesmo com o emblema progressista das mudanças normativas presentes na atual Constituição e aperfeiçoadas no século XXI, especificamente em se tratando do sistema e da política de assistência social. Como assinalado anteriormente, a superação do caráter assistencialista e filantrópico que marcou a trajetória dessa política no Brasil é um desafio que ainda se apresenta cotidianamente a todos os atores que integram seus serviços, programas e projetos (Behring \& Boschetti, 2008). A efetivação de tal empreitada envolve, sobretudo, a consolidação crescente de uma "cultura de direitos", em detrimento da tradicional "cultura da carência" (Carvalho, 2006, p. 143) que, historicamente, prevaleceu na sociedade brasileira. Essa via analítica permite que as reflexões sobre a inserção de psicólogos na Proteção Social Básica considerem dois pontos, além dos aportes teóricometodológicos utilizados pelo profissional em seu dia a dia, a saber: 1) as correlações de força que perpassam sua atuação, na condição de prática social e 2) as implicações da prática profissional nos microespaços sociais onde ela se dá.

Quanto ao primeiro ponto, é preciso, em princípio, que se avalie o terreno contraditório em que se desenvolvem as políticas sociais na América Latina. Carvalho argumenta que esse terreno evidencia "duas configurações estatais em confronto: o Estado Democrático, ampliado na relação com a sociedade civil pela via da política, viabilizando encontros, pactos, parcerias; o Estado Ajustador, restritivo e seletivo sob a égide do mercado" (Carvalho, 2006, p. 122).

Tais conformações delineiam quadros institucionais que interferem nas práticas dos profissionais nas políticas públicas, entre elas na do psicólogo, imprimindo-lhes, às vezes, limitações. Pode-se citar o fato de que, ao mesmo tempo em que há uma crescente ampliação de postos de trabalho para atuação em políticas públicas, tal ampliação ocorre sob precárias condições de trabalho, que vão desde a fragilização de vínculos empregatícios - a exemplo das terceirizações - , que envolvem baixos salários, até situações de precariedade das instalações físicas e dos equipamentos necessários ao desenvolvimento das atividades (Barros, 2007). Tais aspectos contribuem para a rotatividade de profissionais, o que interfere 
sobremaneira na continuidade e na qualidade das ações desenvolvidas.

A propósito do segundo ponto, se considerados também os engendramentos microssociais em suas similaridades e singularidades em relação ao cenário macroestrutural ora exposto, pode-se também dirimir reflexões que enfocam tão-somente os referenciais teóricometodológicos do psicólogo e que, por isso, associam, de forma simplista, a sua práxis em políticas públicas necessariamente a uma conjugação de matizes transformadores, isso porque, a depender das conjunturas locais de gestão e operacionalização, a práxis do psicólogo tanto pode atualizar ordens socialmente excludentes quanto produzir fissuras em tais iniqüidades.

Com efeito, pode haver ambigüidades, inclusive, entre as pretensões dos profissionais e os desdobramentos de sua práxis. É possível, por exemplo, que o trabalho do profissional se proponha a combater os excessos da desigualdade social, ao passo que, no cotidiano, reforce fundamentos que a produzem, caso o dinâmico emaranhado institucional onde ele se situa, em determinadas circunstâncias, respalde a circulação da noção do usuário como "vulnerável" e exalte apenas retoricamente o exercício dialógico, seja na própria gestão municipal seja nos vários espaços onde, de algum modo, ela se materializa.

Sobre tal assunto, Barros observou, em pesquisa sobre a práxis do psicólogo no CRAS, que um entrave comum à prática do psicólogo ocorre na intersecção, por vezes conflitiva, entre as demandas institucionais relacionadas à gestão da Proteção Social Básica e o campo de forças que emerge do contexto microssocial onde se dá a prática cotidiana do psicólogo nesse caso. Segundo aquele autor, as eventuais tensões resultam, muitas vezes, em pressões para que o profissional priorize demandas e temporalidades relacionadas às instituições responsáveis pela gestão da proteção social básica, em detrimento das demandas e temporalidades referentes às comunidades onde estão inseridas tais políticas. É o que verificamos neste trecho:

...na prática desses(as) profissionais, estes(as) têm assumido mais a função de executores(as) de políticas e projetos erigidos em outros âmbitos e a partir de demandas exógenas à comunidade do que a função de criadores(as) de ações a partir da análise e da vivência da atividade comunitária. (Barros, 2007, p. 139)

O panorama acima exposto corrobora a idéia apresentada neste artigo de que o desenvolvimento de políticas públicas e sociais ocorre em meio à existência de projetos políticos diversos em contextos por vezes conflituosos. A análise do cotidiano dessas políticas evidencia, a título de ilustração, a coexistência, em muitos casos, de interesses democráticos e eleitoreiros, o que interfere no trabalho do psicólogo na medida em que pode implicar a obliteração de canais efetivamente dialógicos com os atores sociais, os quais, conforme elucidado, são constituintes dos contornos da práxis de Psicologia comunitária. Em conseqüência, uma das possibilidades decorrentes disso é a restrição da atuação dos psicólogos a práticas normatizantes, a serviço da agenda de grupos políticos à frente das engrenagens governamentais.

Finalmente, aqui se advoga que o olhar crítico para os eventuais pontos de tensão entre a Psicologia comunitária e a Proteção Social Básica é elemento indispensável à atuação do psicólogo nesse espaço. No entanto, vale lançar, paralelamente, a atenção sobre as prováveis vias de articulação entre ambas e sobre os canais possíveis para a efetivação de uma práxis que tenha como horizonte político a emancipação social. Nesse sentido, corrobora-se a afirmação de Yamamoto 
(2007, p. 35), quando destaca que:

...embora tendo como premissa fundamental a negação de que a ação profissional (de qualquer categoria) possa vir a ser o eixo de transformações estruturais, as possibilidades de ação do profissional de Psicologia rumo a práticas diferenciadas também devem ser colocadas no contexto do papel do intelectual numa sociedade contraditória. Nessa direção, o desafio posto para a categoria é ampliar os limites da dimensão política de sua ação profissional, tanto pelo alinhamento com os setores progressistas da sociedade civil, fundamental na correlação de forças da qual resultam eventuais avanços no campo das políticas sociais, quanto pelo desenvolvimento, no campo acadêmico, de outras possibilidades teóricotécnicas, inspiradas em outras vertentes teórico-metodológicas que as hegemônicas da Psicologia.

\section{Considerações finais}

Pensar nas possibilidades de articulação entre a Psicologia e a política de assistência social consiste em um importante esforço que pode contribuir tanto para a efetivação desta como para o aprimoramento daquela, rumo às práxis que rechacem a perpetuação de injustiças sociais crônicas que marcam a realidade brasileira. Em se tratando de atuação no território de vida das famílias com vistas ao fortalecimento de vínculos sociais, buscou-se, neste artigo, lançar argumentos segundo os quais a compreensão de processos subjetivos a partir das interações sociais, mediante a análise, a vivência e a co-construção de atividades comunitárias, figura com centralidade no diálogo entre a Psicologia comunitária e a Proteção Social Básica.

Como desdobramento, supõe-se que concerna ao profissional de Psicologia, nesse caso, contribuir para que pessoas e grupos comunitários ampliem suas possibilidades de se construírem criativamente. Tornase pertinente, em função disso, a problematização de práticas tutelares e de leituras estigmatizantes acerca do contexto comunitário, as quais ainda circulam nos mais variados espaços sociais. Com isso, a práxis psicológica imbrica-se no desafio coletivo de contribuir para a desconstrução do legado assistencialista que historicamente permeou a assistência social no País, a fim de distanciar esse campo da noção de favor e de benesse e de consolidar políticas assentadas na noção de direitos sociais.

A partir dessa direção ético-política, as reflexões ora apresentadas apontam um novo delineamento para o trabalho do psicólogo, que difere do modelo psicoterapêutico-liberal presente no imaginário de muitos daqueles com os quais o psicólogo se depara, entre os quais, mormente, a equipe multiprofissional. Por sinal, cabe ressaltar que a extensão de modelos teórico-técnicos com base na clínica tradicional para a atuação cotidiana dos psicólogos no âmbito da Proteção Social Básica indica um paradoxo da inserção da Psicologia nas políticas públicas nos últimos anos (Dimenstein, 2001; Yamamoto, 2007).

No tocante, especialmente, à incursão da Psicologia no campo da assistência social, estudos como o de Barros (2007), por exemplo, frisam uma contradição que merece destaque. Por um lado, a incursão da Psicologia em espaços como os CRAS tem significado um aumento das oportunidades de trabalho para psicólogos e uma via para que seus serviços estejam mais facilmente ao alcance de populações economicamente desfavorecidas. Por outro lado, tal incursão, em muitos casos, pouco tem servido para que o próprio "fazer psicológico" seja problematizado e para que, em conseqüência, novas formas de intervenções sejam inventadas, isso porque, assim como acontece em outros setores das políticas públicas, a intervenção psicológica tem se notabilizado pela tentativa de reproduzir um modelo clínico convencional, a partir de diferentes abordagens, como a abordagem sistêmica 
de família e a Gestalt-terapia, por exemplo, sem se questionar suficientemente sobre a pertinência da reprodução desse modelo frente às exigências teórico-metodológicas emergentes no campo multiprofissional da assistência social.

Por isso, acreditamos que o desenvolvimento de práticas críticas em Psicologia - que façam jus às potencialidades apresentadas pelas recentes políticas públicas de assistência social - implica o direcionamento da práxis dos psicólogos nesse campo para a potencialização de processos interacionais alinhavados pelo diálogo e pela colaboração entre uma heterogeneidade de atores sociais. Tal direcionamento, por sua vez, remete à criação e/ou ao fortalecimento de ações em rede que partam do e incidam no contexto comunitário em sua complexidade e multidimensionalidade.

Por fim, os apontamentos referentes às limitações do trabalho do psicólogo nos programas, projetos e serviços de Proteção Social Básica não recaem, de um lado, em uma visão romântica, tampouco, por outro lado, em uma atitude pessimista ou mesmo fatalista diante desse contexto emergente. Ao contrário, considera a complexidade tanto da Psicologia quanto das políticas públicas, o que corresponde a um esforço de não tornar ingênuas as análises acerca dessa relação. 


\section{Verônica Morais Ximenes*}

Doutora em Psicologia pela Universidade de Barcelona, professora da Graduação e do Mestrado em Psicologia da Universidade Federal do Ceará, Fortaleza, CE - Brasil. Coordenadora do Núcleo de Psicologia Comunitária (NUCOM).

\section{Luana Rêgo Colares de Paula}

Especialista em Saúde Mental (UECE), mestranda do Programa de Pós-Graduação de Psicologia da Universidade Federal do Ceará, Fortaleza, CE - Brasil. Bolsista da Fundação Cearense de Apoio ao Desenvolvimento Científico e Tecnológico - FUNCAP.

E-mail: luacolares@yahoo.com.br

\section{João Paulo Pereira Barros}

Especialista em Saúde Mental (UECE), mestrando do Programa de Pós-Graduação de Psicologia da Universidade Federal do Ceará, Fortaleza, CE - Brasil. Bolsista da Coordenação de Aperfeiçoamento de Pessoal de Nível Superior - CAPES.

E-mail: jppbarros@yahoo.com.br

*Endereço para envio de correspondência:

Av. Santos Dumont, no 7000, Apto: 903, Bl. A, Papicu. Fortaleza, CE - Brasil - CEP: 60.190-800

E-mail: vemorais@yahoo.com.br

Referências

Recebido 27/05/2008, Reformulado 07/05/2009, Aprovado 20/05/2009

Barros, J. P. P. (2007). Psicologia e políticas públicas: um estudo sobre a práxis do(a) psicólogo(a) no projeto Raízes de Cidadania e nos Centros de Referência da Assistência Social (CRAS) de Fortaleza. Monografia de Conclusão de Curso, Departamento de Psicologia, Universidade Federal do Ceará, Fortaleza.

Behring, R. E., \& Boschetti, I. (2008). Política social: fundamentos e história (4a ed., Vol. 2,). São Paulo: Cortez.

Brasil. (2005a). Política Nacional de Assistência Social - PNAS. Brasília, DF: Ministério do Desenvolvimento Social e Combate à Fome.

Brasil. (2005b). Guia de orientação técnica-SUAS, $n^{\circ}$ 1. Proteção Social Básica de Assistência Social. Recuperado em 25 de março de 2008, do MDS (Ministério do Desenvolvimento Social e Combate à Fome):http://www.mds.gov.br/

Carvalho, A. M. P. (2006). Transformações do Estado na América Latina em tempos de ajustes e resistências: governos de esquerda em busca de alternativas. In A. N. Carleial (Org.), Projetos nacionais e conflitos na América Latina. Fortaleza: Edições UFC/ Edições UECE; México: UNAM.

Conselho Federal de Serviço Social, \& Conselho Federal de Psicologia. (2007). Parâmetros para a atuação de assistentes sociais e psicólogos(as) na Política de Assistência Social. Brasília, DF: Autores.

Costilla, L. F. O. (2006). Pensando o Estado: sociedade política e sociedade civil hoje, no Brasil e no México. In A. N. Carleial (Org.), Projetos nacionais e conflitos na América Latina. Fortaleza: Edições UFC/Edições UECE; México: UNAM.

Diehl, R., Maraschin, C., \& Tittoni, J. (2004). Ferramentas para uma psicologia social. Psicologia em Estudo, 11(2), 407-415.

Dimenstein, M. (2001). O psicólogo e o compromisso social no contexto da saúde coletiva. Psicologia em Estudo, 6(2), 57-63.

Freitas, M. F. Q. (1998). Inserção na comunidade e análise de necessidades: reflexões sobre a prática do psicólogo. Psicologia: Reflexão e Crítica, 11(1), 175-189.
Góis, C. W. L. (1994). Noções de psicologia comunitária (2a ed.). Fortaleza: Edições UFC.

Góis, C. W. L. (2005). Psicologia comunitária-atividade e consciência. Fortaleza: Publicações Instituto Paulo Freire de Estudos Psicossociais.

Höfling, E. M. (2001). Estado e políticas (públicas) sociais. Cadernos CEDES, 21(55), 30-41.

Lane, S. T. M. (2003). Antecedentes históricos da psicologia comunitária. In R. H. F. Campos (Org.), Psicologia social comunitária: da solidariedade à autonomia. São Paulo: Vozes.

Leontiev, A. (1978). O desenvolvimento do psiquismo. Lisboa: Horizonte Universitário.

Montero, M. (2004). Introducción a la psicología comunitaria: desarollo, conceptos y processos. Buenos Aires: Paidós.

Montero, M. (2006). Hacer para transformar: el método en la psicología comunitaria. Buenos Aires: Paidós.

Sawaia, B. B. (2004). O sofrimento ético-político como categoria de análise da dialética exclusão/inclusão. In B. B. Sawaia, As artimanhas da exclusão: análise psicossocial e ética da desigualdade social. São Paulo: Vozes.

Sposati, A., Falcão, M. C., \& Fleury, S. M. T. (1989). Os direitos (dos desassistidos) sociais. São Paulo: Cortez.

Ximenes, V. M., Nepomuceno, B. B., \& Moreira, A. E. M. M. (2007). Cooperação universitária: uma prática comunitária/libertadora a partir da psicologia comunitária. In A. C. F. Cordeiro, E. M. Vieira, \& V. M. Ximenes (Orgs.), Psicologia e(em) transformação social: práticas e diálogos (Coleção Extensão Universitária/UFC). Fortaleza: Aquarela.

Yamamoto, O. H. (2007). Políticas sociais, "terceiro setor" e "compromisso social": perspectivas e limites do trabalho do psicólogo. Psicologia \& Sociedade, 19(1), 30-37.

Zanella, A. V., Da Ros, S. Z., Reis, A. C., \& França, K. B. (2004). Doce, pirâmide ou flor?: o processo de produção de sentidos em um contexto de ensinar e aprender. Interações, 9(17), 91-108. 